\title{
Compartment Syndrome: an Acute Femoral Stress Fracture in a Young Male Athlete
}

\author{
Amelie Kanovsky ${ }^{1,2}$ [D $\cdot$ Ernst J. Mueller ${ }^{2}$ \\ Received: 19 November 2020 / Accepted: 5 April 2021 / Published online: 19 April 2021 \\ (C) The Author(s) 2021
}

\begin{abstract}
The incidence of an acute compartment syndrome (ACS) of the thigh is less than $1 \%$. It is most common in the setting of muscle overuse or muscle injury, as well as secondary to trauma, such as a femoral fracture. We present a case of an ACS in a young, healthy, and semiprofessional athlete with normal coagulation who sustained an acute stress fracture of the distal femur. After the initial fracture osteosynthesis, the patient suffered from a compartment syndrome in the right anterior aspect of the distal thigh. Following rapid surgical fasciotomy, the case was uneventful, and he returned to his preinjury sport level without any neurological consequences. This case confirms that ACS in the thigh is rare, but mainly occurs in young males with a large muscle mass due to participation in various athletic programs. We hypothesize that constant muscle over-usage primes for a larger amount of contused and protruding muscle mass in the small femoral compartment. Hence, the fatigued muscle subjects the bone to an increased mechanical force resulting in an overloading process. This ensues the accumulation of femoral microfractures and primes for the occurrence of an increased rate of stress fractures and an ACS in the thigh.
\end{abstract}

Keywords Compartment syndrome $\cdot$ Femoral stress fracture $\cdot$ Emergency $\cdot$ Athlete $\cdot$ Mechanical stress

\section{Introduction}

The occurrence of an acute compartment syndrome (ACS) in the thigh is a rare observed phenomenon compared to the compartment syndrome in the arm or lower leg. It is most common in the setting of muscle overuse or muscle injury, as well as secondary to trauma, such as a femoral fracture $[8$, $14,15,19,23]$.

In ACS, the interstitial pressure exceeds the capillary perfusion pressure resulting in a loss of perfusion. This further leads to consecutive cellular hypoxia and cellular death. The subsequent pathology includes tissue- and myonecrosis and neurological dysfunctions [26].

We report a case of a semiprofessional young male athlete who presented with a femur stress fracture and developed a

Amelie Kanovsky

amelie.kanovsky@pmu.ac.at

1 Institute of Tendon and Bone Regeneration, Paracelsus Medical University, Spinal Cord Injury \& Tissue Regeneration Center Salzburg, Strubergasse 21, 5020 Salzburg, Austria

2 Department of Trauma Surgery, KABEG-Klinikum Klagenfurt a.W., Klagenfurt, Austria spontaneous compartment syndrome of the thigh post-surgical intervention.

\section{Case Report}

A healthy 39-year-old Caucasian male and semiprofessional marathon runner presented with sudden pain in the distal right thigh after jogging the day before. The patient arrived at the emergency department of a level-II tertiary-care center with the ambulance after collapsing due to intense pain. He participated in several marathons with consistent preparation and additionally engaged in strength-training sessions. The exercise routine included cardiovascular endurance runs three to four times a week between 10 to $25 \mathrm{~km}$ and strength training of the lower extremities. The patient stated that his participation in the last $42.2 \mathrm{~km}$ long marathon was 3 months ago. The day before the accident, his muscles in the thigh were sore but he had no difficulty walking. That morning, the patient went about his usual routine and suddenly experienced pain in the right thigh with no ecchymosis or swelling. After taking a step, the patient collapsed on the floor due to pain and was not able to put weight on the right lower extremity. The patient 
had no relevant medical or surgical history and was not taking steroids.

On clinical evaluation a swelling was noted in the distal right thigh, and there were no initial vascular or neurologic loses in the peripheral leg. The X-ray (a.p. and lateral) of the right femur corresponded to a supracondylar, extraarticular femoral fracture with posterior dislocation (Fig 1, AO 33.A1). The patient was admitted to the trauma surgery medical floor for operative treatment.

The next day, the patient underwent surgery under general anesthesia with osteosynthesis of the insufficiency fracture using a NCB 13 hole right femur plate (Zimmer) (Fig. 2). No drain was added because there was no strong bleeding, and the wound was closed with stitches. The pre- and postoperative laboratory results confirmed a stable hematocrit (33\% post-surgically). The surgical intervention was not accompanied by any complication and the patient was transferred back in a cardiorespiratory stable condition to the trauma surgery medical floor.

During the surgical rounds in the morning, the patient presented with moderate pain, no vascular or neurological injuries, afebrile, no local or peripheral signs of infection, and no thigh circumference enlargement compared to the contralateral side.

Eight hours post-surgery an abrupt status change of the patient was observed: a tense anterior aspect of the right thigh with double the circumference compared to the contralateral side, decreased peripheral sensation to light touch with accompanying dysesthesia, a grade $2 / 5$ extensor and flexor hallucis longus motor strength with no sensation to light touch at hallux level, and palpable pedal pulses. The patient presented with extreme pain in resting position.

Based on the clinical examination, the diagnosis of acute compartment syndrome in the thigh was made and the compartment pressure monitoring has been waived. The patient has been informed and was immediately taken to the operating room to undergo emergent right lateral thigh fasciotomy $48 \mathrm{~h}$ after the primary diagnosed femoral stress fracture.

Intraoperatively, the original incision has been reopened and was extended proximally. All previous sutures were removed. The vastus lateralis muscle was very prominent and swollen but appeared to be pink, contractile, and viable. Above the in situ laying femur plate, no excessive hematoma or blood clot formation could be observed (Fig 3.). Over the open wounds extended NPWT (negative pressure wound therapy)-assisted dermatotraction was applied. Postoperatively, the patient had immediate pain relief and the neurological deficiencies resolved.

The patient was taken back to the operating room 2 days later to initiate wound closure with an elastic vessel loop applied to the wound for dermatotraction in a shoelace manner. Consistent tightening of the elastic vessel loops and skin mobilization led to a wound closure after an additional 7 days and the wound could be closed directly.

There was no complication in the postoperative course and the patient started to be mobilized with partial weight bearing exercises of $10-15 \mathrm{~kg}$ and crutches. The total duration of the hospital stay was 22 days. The follow-up was carried out at 4 , 6 , and 24 weeks postoperative procedure for X-rays, afterwards yearly. Full weight bearing activities could be regained.

\section{Discussion}

Ojike et al. reviewed thigh compartment syndrome cases and noted that $90 \%$ of ACS occurred in the presence of a thigh trauma of which $50 \%$ were due to femur fractures [18].
Fig. 1 X-Ray of the right femur, anterior-posterior (left) and axial (right) view, showing a dislocated supracondylar femoral fracture (AO 33.A1)

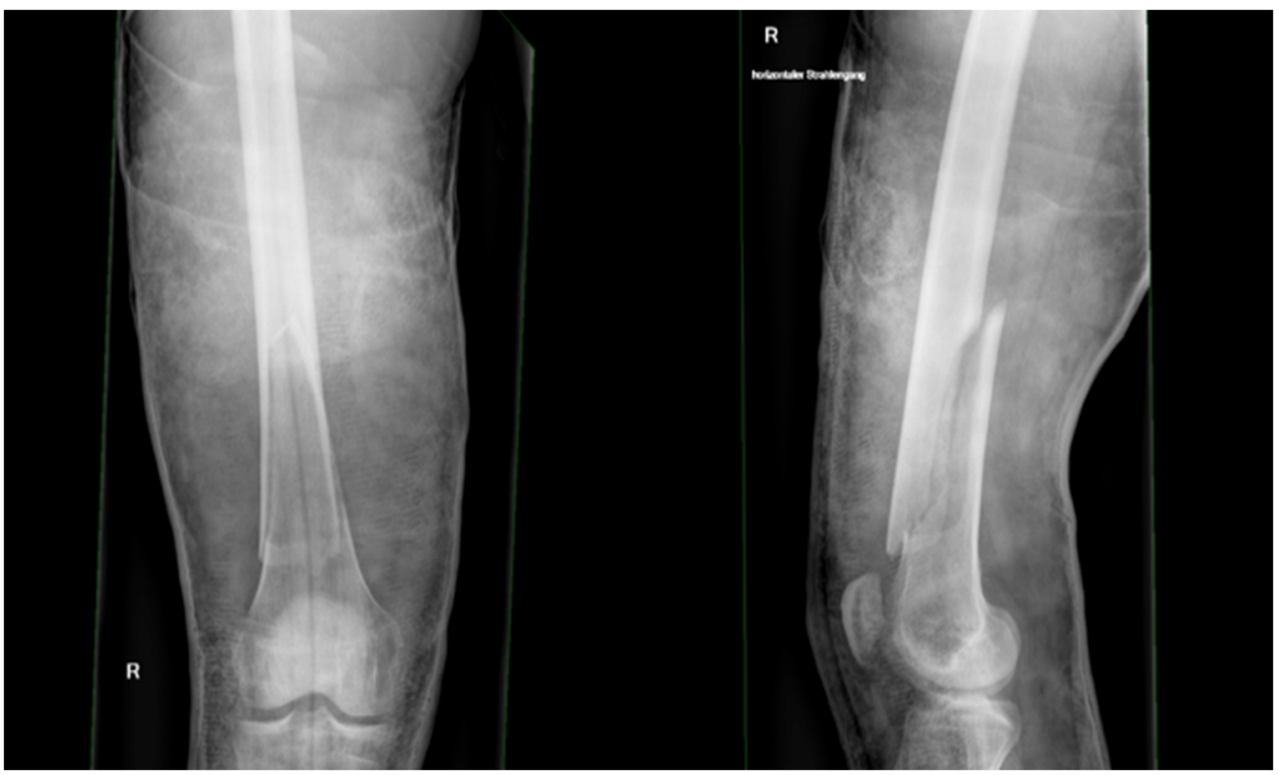


Fig. 2 Intraoperative X-Ray of the right thigh, anterior-posterior (left) and axial (right) view

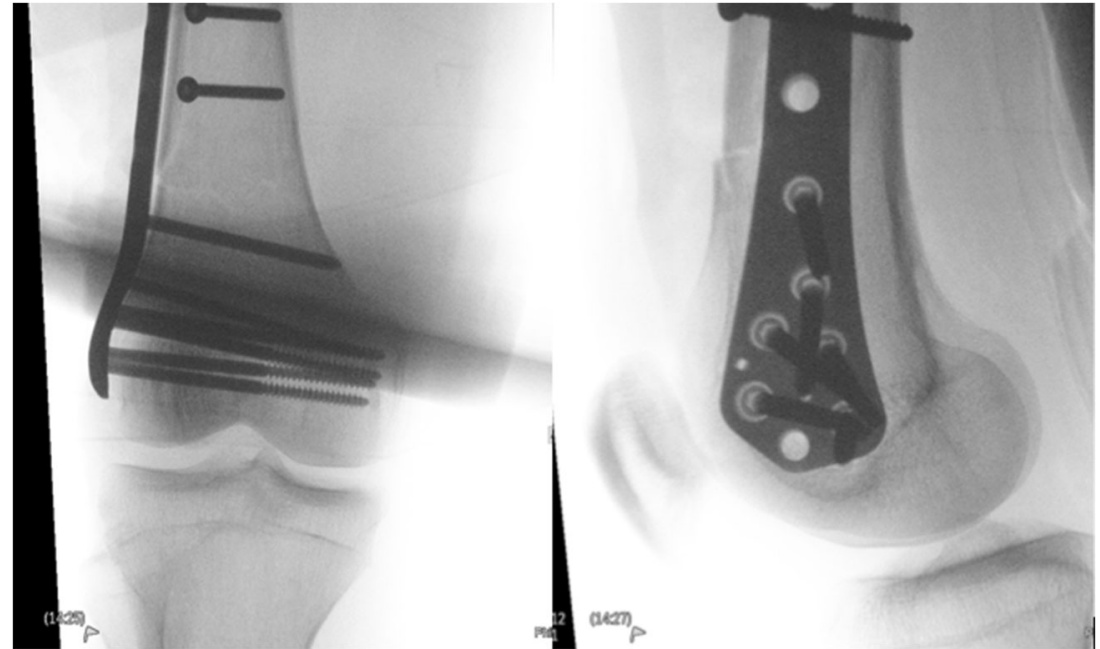

The mean annual incidence of extremity compartment syndromes is 7.3/100,000 for men and 0.7/100,000 for women, which is consistent with previous reports that an ACS in the thigh occurs mostly in male gender and the occurrence is $<1 \%$ $[14,28]$. The reported mean age is between 30 and 40 years of the extremity compartment syndrome [14, 24]. The literature review reports that ACS in the thigh focuses $100 \%$ on male gender with a mean age of 22.8 years [3, 20, 21, 27]. The predisposition includes young, muscular, and athletic males and reflects our presented case $[2,6,14]$.

McQueen et al. [14] hypothesize that the high rate of incidence of ACS in young, athletic males reflects relatively large muscle volumes, while the compartment size (an inelastic fascial envelope) does not change after growth is complete. Thus, young men may have less space for swelling of the muscle after injury. Therefore, large muscle mass combined with an increased risk of trauma appear to be significant risk factors for ACS of the thigh [7, 10-12, 22, 25].

Most authors advocate for surgical release within the classic 8-h window [3, 9, 13, 16-18].

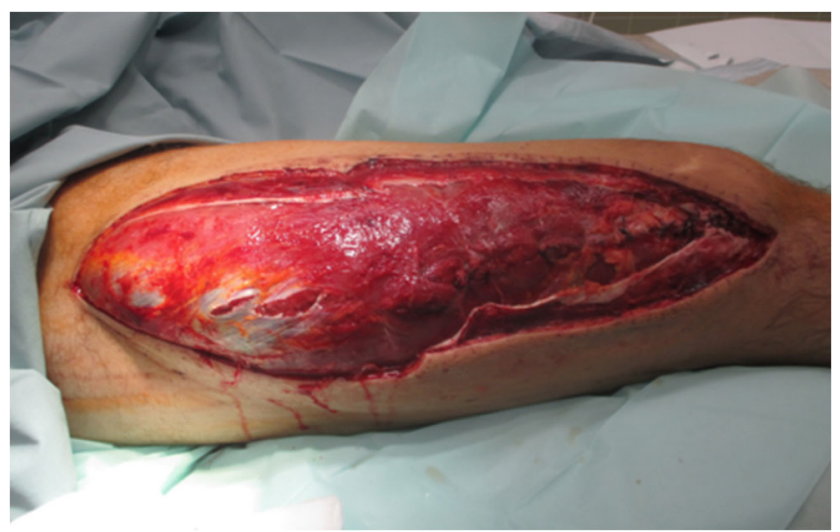

Fig. 3 Intraoperative photograph after compartment fasciotomy of the right thigh
We describe a case of an acute compartment syndrome in the thigh with a principal stress fracture [5]. The fatigued muscle subjects the bone to an increasing force resulting in an overloading process with the accumulation of microfractures $[1,4]$.

To our knowledge, this is the first case report of a patient with an insufficiency fracture who developed a compartment syndrome. We hypothesize that the consistent over-usage and very prominent vastus lateralis muscle in our patient induced the supracondylar femur insufficiency fracture. It secondarily leads to a compartment syndrome due to the already contused and protruding muscle in the small compartment size. We cannot exclude that the compartment syndrome was due to delayed fracture stabilization.

All clinicians, especially in the field of sport and trauma medicine, need to always consider the manifestation of a compartment syndrome in the thigh of a young male athlete and high muscle mass with great suspicion. The measurement of the intracompartment pressure is an adjunct to the examination. Athletes and semiprofessional athletes should also be counseled on the action to prevent stress fractures such as making training adjustments gradually and cross-training.

Funding Open access funding provided by Paracelsus Medical University.

\section{Declarations}

Ethical Approval All procedures performed in studies involving human participants were in accordance with the ethical standards of the institutional and/or national research committee and with the 1964 Helsinki declaration and its later amendments or comparable ethical standards.

Human and Animal Rights and Informed Consent This article does not contain any studies with animals performed by any of the authors. 
Informed Consent Informed consent was obtained from all individual participants included in the study. Additional informed consent was obtained from all individual participants for whom identifying information is included in this article.

Conflict of Interest The authors declare no competing interests.

Open Access This article is licensed under a Creative Commons Attribution 4.0 International License, which permits use, sharing, adaptation, distribution and reproduction in any medium or format, as long as you give appropriate credit to the original author(s) and the source, provide a link to the Creative Commons licence, and indicate if changes were made. The images or other third party material in this article are included in the article's Creative Commons licence, unless indicated otherwise in a credit line to the material. If material is not included in the article's Creative Commons licence and your intended use is not permitted by statutory regulation or exceeds the permitted use, you will need to obtain permission directly from the copyright holder. To view a copy of this licence, visit http://creativecommons.org/licenses/by/4.0/.

\section{References}

1. Aro H, Dahlstrom S (1986) Conservative management of distraction-type stress fractures of the femoral neck. J Bone Joint Surg (Br) 68(1):65-67

2. Badhe S, Baiju D, Elliot R, Rowles J, Calthorpe D (2009) The 'silent' compartment syndrome. Injury. 40:220-222

3. Colosimo AJ, Ireland ML (1992) Thigh compartment syndrome in a football athlete: a case report and review of the literature. Med Sci Sports Exerc 24:958-963

4. Egol KA, Koval KJ, Kummer F, Frankel VH (1998) Stress fractures of the femoral neck. Clin Orthop Relat Res 348:72-78

5. Fredericson M, Jennings F, Beaulieu C, Matheson GO (2006) Stress fractures in athletes. Top Magn Reson Imaging 17(5):309325

6. Gorman PW, McAndrew MP (1987) Acute anterior compartment syndrome of the thigh following contusion. A case report and review of the literature. J Orthop Trauma 1:68-70

7. Gourgiotis S, Villias C, Germanos S, Foukas A, Ridolfini MP (2007) Acute limb compartment syndrome: a review. J Surg Educ 64(3):178-186

8. Gutfraynd A, Philpott S (2016) A case of acute atraumatic compartment syndrome of the thigh. J Emerg Med 51(3):45-47

9. Kahan JS, McClellan RT, Burton DS (1994) Acute bilateral compartment syndrome of the thigh induced by exercise. A case report. J Bone Joint Surg Am 76(7):1068-1071

10. King TW, Lermann OZ, Carter JJ, Warren SM (2010) Exertional compartment syndrome of the thigh: a rare diagnosis and literature review. J Emerg Med 39(2):93-99

11. Matsen FA 3rd, Winquist RA, Krugmire RB Jr (1980) Diagnosis and management of compartmental syndromes. J Bone Joint Surg Am 62(2):286-291
12. McCaffrey DD, Clarke J, Bunn J, McCormack M (2009) Acute compartment syndrome of the anterior thigh in the absence of fracture secondary to sporting trauma. J Trauma 66:1238-1242

13. McDonald LS, Mitchell RJ, Deaton TG (2012) Bilateral compartment syndrome of the anterior thigh following functional fitness exercise: a case report. Mil Med 177(8):993-996

14. McQueen MM, Gaston P, Court-Brown C (2000) Acute compartment syndrome. Who is at risk? J Bone Joint Surg 82(2):200-203

15. McQuerry JL, Burnham JM, Ireland ML, Wright RD (2018) Delayed presentation of compartment syndrome of the thigh in a previously undiagnosed Factor VII-deficient high school football athlete: a case report. J Bone Joint Surg Case Connect 8(1):e1-e4

16. Mithoefer K, Lhowe DW, Vrahas MS, Altman DT, Erens V, Altman GT (2006) Functional outcome after acute compartment syndrome of the thigh. J Bone Joint Surg Am 88(4):729-737

17. Nau T, Menth-Chiari WA, Seitz H, Vecsei V (2000) Acute compartment syndrome of the thigh associated with exercise. Am J Sports Med 28(1):120-122

18. Ojike N, Roberts C, Giannoudis P (2010) Compartment syndrome of the thigh: a systemic review. Injury. 41:133-136

19. Patti BN, Pfefferle KJ, Meyer T (2014) Bilateral compartment syndrome of the thigh in a college football athlete. J Bone Joint Surg Case Connect 4(1): 1-4

20. Riede U, Schmid M, Romero J (2007) Conservative treatment of an acute compartment syndrome of the thigh. Arch Orthop Trauma Surg 127:269-275

21. Roeoesser B, Bengtson S, Haegglund G (1991) Acute compartment syndrome from anterior thigh muscle contusion: a report of eight cases. J Orthop Trauma 5:57-59

22. Saber A (2014) Compartment syndromes. J Acute Dis 3:169-177

23. Schwarz JT Jr, Brumback RJ, Lakatos R, Poka A, Bathon GH, Burgess AR (1989) Acute compartment syndrome of the thigh. A spectrum of injury. J Bone Joint Surg Am 71(3):392-400

24. Shadgan B, Pereira G, Menon M, Jafari S, Darlene Reid W, O'Brien PJ (2015) Risk factors for acute compartment syndrome of the leg associated with tibial diaphyseal fractures in adult. J Orthop Traumatol 16:185-192

25. Smith RDJ, Rust-March H, Kluzek S (2015) Acute compartment syndrome of the thigh in a rugby player. Case Reports, bcr2015210856

26. Taylor RM, Sullivan MP, Mehta S (2012) Acute compartment syndrome: obtaining diagnosis, providing treatment, and minimizing medicolegal risk. Curr Rev Muskuloskelet Med 5:206-213

27. Winternitz WA, Metheny JA, Wear LC (1992) Acute compartment syndrome of the thigh in sports-related injuries not associated with femoral fractures. Am J Sports Med 20:476-478

28. Zuchelli D, Divaris N, McCormack JE, Huang EC, Chaudhary ND, Vosswinkel JA, Jawa RS (2017) Extremity compartment syndrome following blunt trauma: a level I trauma center's 5-year experience. J Surg Res 217:131-136

Publisher's Note Springer Nature remains neutral with regard to jurisdictional claims in published maps and institutional affiliations. 